\title{
PERAN PEMEDIASI LOCUS OF CONTROL PADA PENGARUH FINANCIAL KNOWLEDGE DAN FINANCIAL ATTITUDE TERHADAP FINANCIAL MANAGEMENT BEHAVIOR
}

\author{
Bella Cahyaningrum \\ Universitas Ahmad Dahlan \\ bellachyaa36@gmail.com \\ Muhammad Ali Fikri \\ Universitas Ahmad Dahlan \\ muhammad.fikri@mgm.uad.ac.id
}

\begin{abstract}
This study aims to determine the effect of financial knowledge and financial attitude on financial management behavior with the locus of control as a mediating variable. The population of this study were students of the Faculty of Economics and Business in Yogyakarta, totalling 198.144 respondents. Sampling in this study used the purposive sampling technique by using several criteria. The number of samples in this study was 96 respondents. The method of collecting data is by using a questionnaire. Data analysis tools using SmartPLS version 3.0 software. Scale test results of the instruments used in this study meet the validity and reliability analysis standard. Direct significance testing of the hypothesis shows that financial knowledge has a positive effect on financial management behavior, locus of control mediates the positive effect of financial knowledge on financial management behavior, the financial attitude has a positive effect on financial management behavior, and locus of control mediates the positive effect of financial attitude on financial management behavior.
\end{abstract}

Keywords: financial attitude; financial knowledge; financial management behavior; locus of control.

\section{PENDAHULUAN}

Beberapa tahun terakhir, praktik manajemen keuangan mendapatkan perhatian serius dalam organisasi atau masyarakat dalam arti luas (Mien \& Thao, 2015). Masyarakat dewasa ini seringkali dinilai kurang bertanggungjawab pada sumber pengelolaan keuanganya dan kurang memiliki perilaku manajemen keuangan (financial management behavior) yang baik (Borden et al.,2008). Hal ini disebabkan karena masyarakat saat ini tumbuh di antara fasilitas dan gaya hidup yang mewah, pembuatan dan penggunaan kartu kredit yang mudah, serta budaya hutang yang dianggap lumrah (Borden et al., 2008). Pengetahuan dasar tentang keuangan sangat dibutuhkan dalam mengelola keuangan masyarakat khususnya generasi muda untuk mengarahkan kepada financial management behavior yang baik (Borden et al.,2008).

Financial management behavior pada prinsipnya adalah kegiatan pengelolaan uang yang dilakukan oleh individu atau masyarakat dalam kehidupan sehari-hari untuk mencapai kesejahteraan (Dwiastanti, 2017). Individu perlu mempunyai kemampuan dalam hal mengelola keuangan agar nantinya keuangan tersebut dapat dimanfaatkan untuk memenuhi dan mencukupi kebutuhannya. Apabila financial management behavior individu dikatakan baik, maka individu tersebut akan terhindar dari masalah keuangan. Agar dapat menghindari financial distress diperlukan kecerdasan keuangan yang menjadi kecerdasan individu dalam mengelola keuangan pribadinya (Dwiastanti, 2017). Financial management behavior dapat dikatakan sehat apabila kegiatan perencanaan keuangan, pengelolaan keuangan, dan pengendalian keuangan berjalan dengan baik. Hal itu bisa dilihat dari cara individu dalam melakukan pengelolaan arus keluar, manajemen perkreditan, manajemen investasi serta tabungan (Hilgert, 2003). Kearifan financial management behavior pribadi sangat erat kaitannya dengan kemampuan dan financial knowledge (Hilgert, 2003).

Tingginya financial management behavior seseorang dapat ditentukan dari financial knowledge yang dimiliki. Financial knowledge merupakan kompetensi seseorang untuk melakukan suatu tindakan rasional dan penilaian terhadap pengelolaan keuangan (Amanah et al.,2016). Financial knowledge 
diasumsikan sebagai kemampuan individu dalam menguasai berbagai hal yang berkaitan dengan keuangan dan didalamnya menyangkut keterampilan dan alat keuangan (Andrew \& Linawati, 2014). Tang \& Baker (2016) serta Nobriyani \& Haryono (2019) menunjukkan financial management behavior berpengaruh positif terhadap financial knowledge. Meskipun beberapa penelitian terdahulu menunjukkan hasil bahwa financial knowledge memiliki pengaruh positif pada financial management behavior, namun penelitian terdahulu bisa dikatakan belum konsisten. Inkonsistensi hasil penelitian terdahulu dapat dilihat dari penelitian Rizkiawati \& Haryono (2018) yang menunjukkan bahwa financial knowledge tidak memiliki pengaruh pada financial management behavior. Hasil analisa di atas menjadi tujuan penelitian ini yang ingin menguji lebih lanjut tentang pengaruh positif financial knowledge terhadap financial management behavior.

Individu dengan financial knowledge yang tinggi, maka pengetahuan dan pemahaman tentang keuangan juga baik sehingga akan menciptakan financial management behavior yang baik juga. Apabila financial knowledge dari setiap individu tinggi, maka financial management behavior yang dimiliki akan baik juga (Asaff et al., 2019). Financial knowledge yang baik dari setiap individu akan membentuk locus of control yang baik (Sriwidodo, 2015). Al Kholillah \& Iramani (2013) dan Sriwidodo (2015) menunjukkan financial knowledge memiliki pengaruh positif terhadap locus of control. Individu dengan financial knowledge yang tinggi mampu memelajari dan mengalokasikan pendapatannya dengan baik, bertanggung jawab atas keuangan pribadinya sehingga hal tersebut akan meningkatkan kemampuan locus of control atas hasil perilakunya (Ida \& Dwinta, 2010). Jorgensen et al. (2017) dan Pradiningtyas \& Lukiastuti (2019) menunjukkan bahwa locus of control memiliki pengaruh positif terhadap financial management behavior. Individu dengan locus of control yang baik menunjukkan bahwa individu tersebut memiliki tanggung jawab terhadap dirinya, berhati-hati dalam pengelolaan keuangannya, dan pada akhirnya akan meningkatkan financial management behavior (Al Kholilah \& Iramani, 2013).

Locus of control dapat berfungsi menjadi variabel mediasi pada pengaruh financial knowledge terhadap financial management behaviour (Aydemir \& Aren, 2017). Aydemir \& Aren (2017) menunjukkan bahwa locus of control mampu berperan sebagai variabel mediasi pada pengaruh positif financial knowledge terhadap financial management behavior. Hal ini menunjukkan individu dengan financial knowledge yang baik dapat meningkatkan kemampuan locus of control dalam pengelolaan keuangan serta secara bersama-sama dapat meningkatkan financial management behavior untuk kesejahteraan hidupnya (Rahmawati \& Haryono, 2020).

Financial attitude menggambarkan kondisi pikiran, penilaian serta pendapat individu terhadap keuangan (Pankow, 2003). Selanjutnya, financial attitude juga mengacu pada kemampuan individu dalam dan menghadapi persoalan keuangan pribadi dengan tolak ukur tanggapan terhadap suatu pendapat atau argumen (Marsh, 2006). Marsh (2006) menambahkan bahwa sikap dan perilaku individu dalam hal keuangan dapat dibantu dengan adanya financial attitude. Penelitian terdahulu dari Mien \& Thao (2015), Potrich et al. (2015), serta Budiono (2020) menunjukkan bahwa financial attitude memiliki pengaruh positif terhadap financial management behavior. Individu dengan financial attitude yang baik berdampak pada meningkatnya kualitas pandangan dan pola pikir terhadap keuangan di masa yang akan datang di mana setiap individu akan berusaha untuk melakukan pengelolaan uang dengan baik (Asaff et al.,2019).

Herdjiono \& Damanik (2016) dan Dwiastanti (2017) menunjukkan terdapat pengaruh positif financial attitude terhadap locus of control. Artinya, semakin baik sikap individu terhadap keuangan yang dimiliki akan berdampak pada locus of control, dan pada akhirnya memengaruhi individu dalam mengambil sikap atau keputusan (Herdjiono \& Damanik, 2016). Individu yang mempunyai financial attitude yang baik akan terdorong untuk mempunyai locus of control yang baik pula, dengan demikian orang tersebut akan mengontrol dirinya agar selalu memiliki perasaan untuk selalu melakukan kegiatan keuangan yang tidak merugikan (Dwiastanti, 2017). Hasil penelitian Jorgensen et al. (2017) serta Pradiningtyas \& Lukiastuti (2019) menunjukkan bahwa locus of control memiliki pengaruh positif terhadap financial management behavior. Artinya, semakin tinggi tingkat locus of control dalam diri individu, maka financial management behavior individu tersebut juga akan semakin baik. 
Penelitian dari Amanah et al. (2016) serta Pradiningtyas \& Lukiastuti (2019) menunjukkan locus of control mampu berperan sebagai mediasi pada pengaruh positif financial attitude terhadap financial management behavior. Individu dengan financial attitude yang baik berdampak pada locus of control individu tersebut dan juga pada akhirnya memengaruhi financial management behavior (Dwiastanti, 2017).

Subyek dari penelitian ini adalah mahasiswa dari Fakultas Ekonomi dan Bisnis yang ada di Daerah Istimewa Yogyakarta, dengan pertimbangan: pertama, indeks literasi keuangan di Provinsi Daerah Istimewa Yogyakarta berdasarkan hasil Survei Nasional Literasi Keuangan yang dipublikasikan oleh Otoritas Jasa Keuangan (2019) tentang indeks literasi keuangan yang ada di Provinsi Daerah Istimewa (D.I) Yogyakarta sekitar 58,53\% dan di Indonesia menempati posisi kedua setelah Daerah Khusus Ibukota (DKI) Jakarta sehingga hal ini menarik untuk diteliti karena diasumsikan masyarakat di D.I Yogyakarta memiliki pemahaman yang baik terhadap literasi keuangan. Kedua, mahasiswa Fakultas Ekonomi dan Bisnis telah mempelajari mata kuliah yang berhubungan dengan keuangan seperti manajemen keuangan, akuntansi keuangan menengah, analisis laporan keuangan, sistem keuangan, dan lain-lain yang telah dipelajari dalam perkuliahan, sehingga mahasiswa diharapkan mempunyai pemahaman dan pengetahuan tentang keuangan yang baik. Penelitian ini bertujuan untuk mengetahui peran pemediasi locous of control pada pengaruh financial knowledge dan financial attitude terhadap financial management behavior pada mahasiswa Fakultas Ekonomi dan Bisnis di Daerah Istimewa Yogyakarta.

\section{KAJIAN PUSTAKA DAN PENGEMBANGAN HIPOTESIS}

\section{Financial Management Behavior}

Financial management behavior berkaitan dengan kemampuan individu dalam mengatur yaitu perencanaan, penganggaran, pemeriksaan, pengelolaan, pengendalian, pencarian dan penyimpanan dana keuangan sehari-hari (Al Kholilah \& Iramani, 2013). Munculnya financial management behavior merupakan dampak dari besarnya hasrat individu untuk mencukupi kebutuhan hidupnya sesuai dengan tingkat pendapatan yang didapatkannya (Al Kholilah \& Iramani, 2013). Fokus dalam Financial management behavior adalah determinasi, akuisisi, alokasi dan pemanfaatan sumber daya keuangan yang biasanya disertai dengan memikirkan target secara luas (Mien \& Thao, 2015). Humaira \& Sagoro (2018) mengungkapkan bahwa financial management behavior dapat juga berhubungan dengan afektivitas manajemen dana, di mana arus dana harus diarahkan sesuai dengan rencana yang telah ditetapkan. Financial management behavior dalam konteks mahasiswa adalah financial management behavior pribadi mahasiswa itu sendiri dalam mengelola penggunaan uang saku yang diberikan oleh orang tua dengan penuh rasa tanggungjawab (Herawati, 2015)

\section{Financial Knowledge}

Individu pada umumnya mengharapkan kondisi keuangan yang sejahtera dengan dapat melakukan keputusan yang cerdas mengenai cara mengelola keuangannya dengan bijak. Untuk tercapainya keadaan yang diharapkan, individu perlu mempunyai dan memahami segala sesuatu yang berhubungan dengan keuangan, atau dengan kata lain individu harus mempunyai financial knowledge yang baik (Huston, 2010). Menurut Huston (2010) financial knowledge merupakan bagian yang menyatu dengan literasi keuangan. Silvy \& Yulianti (2013) menjelaskan bahwa financial knowledge merupakan segala sesuatu tentang keuangan yang dihadapi atau yang terjadi di dalam kehidupan sehari-hari. Sedangkan Al Kholilah \& Iramani (2013) mendefinisikan financial knowledge sebagai pemahaman individu tentang berbagai hal yang berkaitan mengenai dunia keuangan.

\section{Financial Attitude}

Pankow (2003) menjelaskan bahwa attitude yang baik dapat mempengaruhi perilaku individu termasuk dalam mengatur financial management behavior khususnya untuk mencapai target (goals) keuangannya. Dapat disimpulkan bahwa financial attitude dapat mempengaruhi financial management behavior individu. Individu dengan tingkat financial attitude yang baik akan menunjukkan pola pikir yang baik mengenai uang sehingga dapat mencerminkan perilaku yang baik 
dalam mengelola keuangannya (Pankow, 2003). Financial attitude juga berkaitan dengan sikap individu yang diterapkan dalam keuangan pribadinya melalui penilaian, pandangan, dan pemikirannya (Amanah et al.,2016). Sikap inilah yang nantinya dapat menjadi prinsip keuangan individu untuk memertahankan dan juga menciptakan nilai dalam mengambil suatu keputusan dan mengelola keuangan secara tepat (Rizkiawati \& Haryono, 2018).

\section{Locus of Control}

Locus of control diartikan sebagai persepsi individu tentang sebab-sebab keberhasilan atau kegagalan dalam melaksanakan pekerjaannya (Silvy \& Yulianti, 2013). Locus of control dalam orientasinya dibagi menjadi dua yaitu locus of control internal dan locus of control eksternal. Individu yang mempunyai locus of control internal mempunyai kepercayaan diri yang lebih pada dirinya sendiri, sedangkan sebaliknya, pada individu yang memiliki locus of control eksternal, individu akan meyakini bahawa semua kejadian bergantung pada takdir dan lingkungan sekitar. Uraian ini mempunyai makna bahwa kejadian bergantung pada takdir dan lingkungan di sekitarnya. Hal ini mempunyai arti bahwa individu dengan locus of control internal kemungkinannya lebih besar untuk melakukan tugas-tugas yang sulit dan memiliki resiko (hasilnya tidak pasti) dibanding individu dengan locus of control eksternal (Ariani et al.,2016).

\section{Pengaruh antar variabel}

Robb \& Woodyard (2011) dan Zakaria et al. (2012) mengatakan financial knowledge memengaruhi perilaku dari masing-masing individu untuk bijaksana secara keuangan. Hasil penelitian dari Shahrabani (2012), Mien \& Thao (2015), Tang \& Baker (2016), serta Amanah et al. (2016) menunjukkan financial knowledge memiliki pengaruh positif pada financial management behavior. Artinya, individu dengan financial knowledge yang tinggi, maka pengetahuan dan pemahaman tentang dunia keuangan juga memadai dan akan memengaruhi financial management behavior (Asaff et al.,2019). Dengan demikian, financial knowledge menjadi hal yang sangat dibutuhkan dalam dunia keuangan karena financial knowledge yang tinggi akan berpengaruh pada financial management behavior dari masing-masing individu, dan pada akhirnya menimbulkan kesadaran diri individu untuk mengatur keuangan dengan baik (Assaf et al.,2019). Berdasarkan penjelasan di atas, dapat dirumuskan hipotesis pertama:

\section{H1: Financial knowledge berpengaruh positif terhadap financial management behavior.}

Ajzen (2011) dalam theory of planned behavior mengatakan perilaku dan niat merupakan sebuah fungsi dari sikap individu (attitude), kendali perilaku yang dipersepsikan (perceived behavioral control), dan norma subjektif (subjective norm). Dalam penelitian ini kendali perilaku digambarkan oleh financial knowledge, niat digambarkan oleh locus of control, dan perilaku diwakilkan oleh financial management behavior. Individu dengan financial knowledge yang baik akan menciptakan locus of control yang tinggi. Individu akan mengontrol diri untuk selalu mengambil keputusan yang tepat dan cermat sesuai dengan pengetahuan mereka. Hal tersebut sesuai dengan theory of planned behavior yang menjelaskan semakin besar perceived behavioral control, maka locus of control dalam diri individu akan semakin kuat untuk melakukan perilaku yang sedang dipertimbangkan dan secara bersama-sama akan meningkatkan financial management behavior untuk kesejahteraan hidupnya. Locus of control merupakan konsep psikologi mengenai kepercayaan individu terhadap kejadian yang dapat berpengaruh kepada mereka. Dengan demikian, individu akan mengontrol diri untuk selalu mengambil keputusan yang tepat dan cermat sesuai dengan pengetahuan mereka sehingga financial knowledge individu yang semakin tinggi akan meningkatkan locus of control (Asih \& Khafid, 2020).

Financial knowledge tidak akan berguna secara maksimal apabila tidak diimbangi dengan rasa tanggungjawab pribadi yang tinggi (Perry \& Morris, 2005). Lebih lanjut Perry \& Morris (2005) mengatakan bahwa sumber daya keuangan dan pengetahuan keuangan yang dimiliki oleh individu tidak dimanfaatkan secara maksimal karena mereka menilai mampu mengendalikan nasibnya. Financial knowledge yang diimbangi dengan locus of control akan membantu individu bertanggungjawab dengan financial management behavior (Perry \& Morris, 2005). Hasil penelitian yang dilakukan oleh Silvy dan Yulianti (2013) menjelaskan individu dengan financial knowledge 
yang tinggi berdampak pada perilaku untuk mengelola keuangan (financial management behavior) yang lebih bijak. Financial management behavior secara bijak juga harus diimbangi dengan locus of control yang baik (Silvy \& Yulianti, 2013). Penelitian terdahulu dari Al Kholillah \& Iramani (2013) serta Dwiastanti (2017) menunjukkan bahwa financial knowledge mempunyai pengaruh positif terhadap locus of control. Individu dengan financial knowledge yang tinggi mampu memelajari dan mengatur keuangannya dengan baik, sehingga hal tersebut akan meningkatkan kemampuan locus of control atas hasil perilakunya (Ida \& Dwinta, 2010).

Jorgensen et al. (2017) serta Pradiningtyas \& Lukiastuti (2019) menunjukkan bahwa locus of control memiliki pengaruh positif pada financial management behavior. Locus of control menggambarkan pandangan individu terhadap kondisi yang akan datang dan mempengaruh keputusan yang akan diambilnya. Maka dari itu, locus of control harus dimiliki oleh masing-masing individu agar bertanggungjawab atas keputusan yang sudah diambilnya. Individu dengan tingkat locus of control yang tinggi, maka individu akan bertanggungjawab dengan keputusan keuangan yang diambilnya, dan tingginya locus of control akan berpengaruh pada financial management behavior yang semakin baik (Mien \& Thao, 2015).

Dari penjelasan di atas, individu dengan financial knowledge yang baik dapat meningkatkan kemampuan locus of control terutama dalam pengelolaan keuangan serta secara bersama-sama dapat meningkatkan financial management behavior. Hasil penelitian Aydemir \& Aren (2017) menunjukkan bahwa locus of control mampu berperan sebagai pemediasi pada pengaruh positif financial knowledge terhadap financial management behavior. Berdasarkan penjelasan di atas, dapat dirumuskan hipotesis kedua:

$\mathrm{H} 2$ : Locus of control memediasi pada pengaruh positif financial knowledge terhadap financial management behavior.

Theory of planned behavior mengatakan sikap dianggap sebagai contoh pertama dari intensi perilaku (Ajzen, 2011). Sikap merupakan bentuk kepercayaan individu dalam mempresentasikan suatu perilaku. Sikap ditentukan oleh kepercayaan individu terhadap konsekuensi dari suatu perilaku (behavioral beliefs) dan diukur menggunakan hasil evaluasi konsekuensinya (out come evaluation). Sikap tersebut dipercaya mempunyai pengaruh secara langsung pada intensi perilaku individu dan dikaitkan dengan norma subjektif. Norma subjektif diperkirakan berperan sebagai suatu fungsi dari beliefs secara spesifik untuk mempresentasikan perilaku (Ajzen, 2011).

Mien \& Thao (2015), Potrich et al. (2015), serta Pusparani \& Krisnawati (2019) menunjukkan financial attitude memiliki pengaruh positif terhadap financial management behavior. Individu dengan financial attitude yang baik menciptakan pandangan dan pola pikir tentang keuangan dimasa yang akan datang. Semakin baik financial attitude dari masing-masing individu berdampak pada semakin baik financial management behavior yang dimiliki individu (Asaff et al.,2019). Financial attitude membentuk karakter dari setiap individu dalam pengelolaan keuangan dan bagaimana caranya mereka menaggapi permasalahan keuangan. Dengan demikian, individu dengan financial attitude yang semakin baik pada umumnya akan lebih bijak dalam mengambil keputusan khususnya yang berkaitan dengan financial management behavior (Asaff et al.,2019) karena keputusan yang diambil akan menunjukkan pada financial management behavior individu (Asaff et al.,2019). Berdasarkan penjelasan di atas, dapat dirumuskan hipotesis ketiga:

\section{H3: Financial attitude berpengaruh positif terhadap financial management behavior.}

Theory of planned behavior mengatakan niat perilaku merupakan suatu fungsi dari adanya sikap, norma subjektif, dan kendali perilaku yang dipersepsikan. Pada penelitian ini sikap diwakili oleh financial attitude, sedangkan niat diwakili oleh locus of control, dan perilaku diwakili oleh financial management behavior. Apabila terdapat sikap yang positif, memiliki dukungan dari orang sekitar yang berada dilingkungannya, serta terdapat persepsi kemudahan karena tidak adanya hambatan untuk 
Bella Cahyaningrum \& Muhammad Ali Fikri. Peran Pemediasi Locus of Control pada Pengaruh Financial Knowledge dan Financial Attitude terhadap Financial Management Behavior

berperilaku, maka hal ini akan mengakibatkan niat individu untuk berperilaku akan semakin tinggi (Ajzen, 2011).

Jorgensen et al. (2017), Mien \& Thao (2015), dan Dwiastanti (2017) mengungkapkan bahwa adanya pengaruh positif financial attitude pada locus of control. Individu dengan financial attitude yang baik akan mendorongan locus of control yang baik juga (Dwiastanti, 2017). Individu akan mengontrol diri untuk selalu memiliki perasaan untuk selalu melakukan kegiatan keuangan yang tidak merugikan. Oleh karena itu, financial attitude yang baik pada diri individu akan menguatkan locus of control untuk mempertimbangkan suatu tindakan (Asih \& Khafid, 2020).

Locus of control menggambarkan pandangan individu terhadap kondisi yang akan datang dan mempengaruh keputusan yang akan diambilnya. Maka dari itu, locus of control harus dimiliki oleh masing-masing individu agar bertanggungjawab atas keputusan yang sudah diambilnya. Individu dengan tingkat locus of control yang tinggi, maka individu akan bertanggungjawab dengan keputusan keuangan yang diambilnya, sehingga tingginya locus of control akan berpengaruh pada financial management behavior yang semakin baik (Mien \& Thao, 2015). Hasil penelitian didukung oleh Jorgensen et al. (2017) serta Pradiningtyas \& Lukiastuti (2019) yang menjelaskan bahwa locus of control memiliki pengaruh positif pada financial management behavior.

Tanpa adanya locus of control yang baik dalam financial management behavior, maka akan sulit bagi individu untuk mengontrol dirinya agar dapat memanfaatkan penerimaan yang diterima untuk memenuhi keperluan yang memang dibutuhkan saja (Asih \& Khafid, 2020). Tingginya locus of control individu memicu dirinya untuk mengalokasikan uang yang dimiliki sesuai rencana sehingga tujuan keuangannya dapat tercapai tanpa mengalami kendala yang berarti (Asih \& Khafid, 2020). Hasil penelitian yang dilakukan Aminatuzzahra (2014), Amanah et al., (2016), serta Pradiningtyas \& Lukiastuti (2019) menunjukkan locus of control mampu berperan sebagai mediasi pada pengaruh financial attitude terhadap financial management behavior. Semakin baik financial attitude yang dimiliki individu akan meningkatkan locus of control. Perasaan untuk mendukung atau tidak mendukung suatu pandangan keuangan ini akan membentuk locus of control pada diri individu. Hal tersebut akhirnya akan menghasilkan financial management behavior yang bertanggungjawab. Pada akhirnya terdapat keterkaitan antara meningkatnya financial attitude yang dimiliki oleh individu akan membentuk locus of control yang baik dan pada akhirnya menciptakan financial management behavior yang baik pula (Dwiastanti, 2017). Berdasarkan penjelasan di atas, dapat dirumuskan hipotesis keempat:

H4: Locus of control memediasi pada pengaruh positif financial attitude terhadap Financial Management Behavior.

Gambar 1 menunjukkan model penelitian peran pemediasi locus of control pada pengaruh financial knowledge dan financial attitude terhadap financial management behavior.

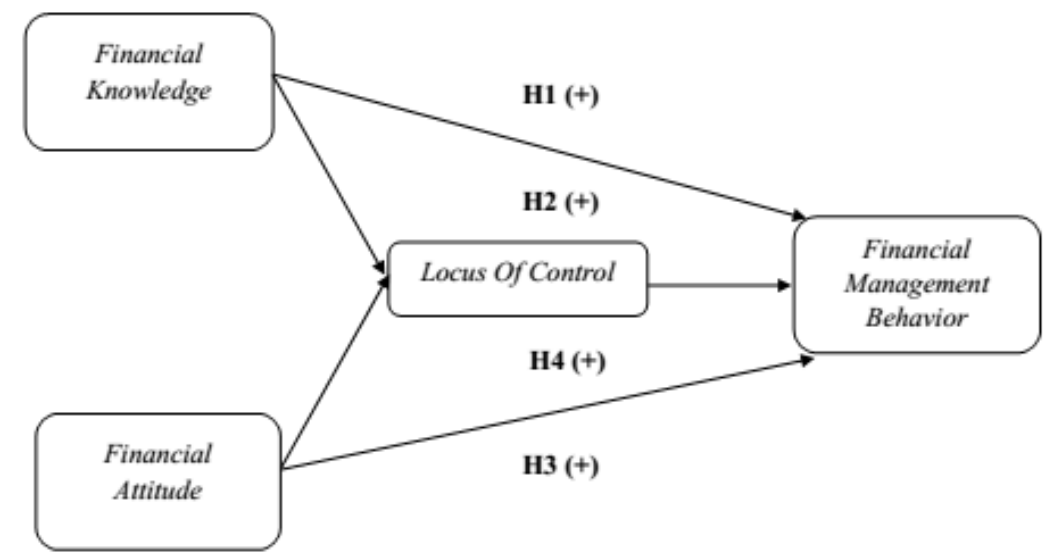

Gambar 1. MODEL PENELITIAN 


\section{METODE PENELITIAN}

Populasi dalam penelitian ini adalah Mahasiswa Fakultas Ekonomi dan Bisnis di Daerah Istimewa Yogyakarta yang berjumlah 198.144 responden (Pangkalan Data Pendidikan Tinggi, 2020). Populasi dalam penelitian cukup besar dan tidak memungkinkan bagi peneliti untuk menggunakan semua responden, misalnya karena keterbatasan biaya, waktu, dan tenaga. Maka dari itu, teknik pengambilan sampel yang digunakan dalam penelitian yaitu teknik purposive sampling. Adapun kriteria mahasiswa sebagai sampel dalam penelitian ini: (1) Mahasiswa Fakultas Ekonomi dan Bisnis di Daerah Istimewa Yogyakarta yang telah mengambil mata kuliah yang berhubungan dengan keuangan seperti manajemen keuangan, akuntansi keuangan menengah, analisis laporan keuangan, sistem keuangan, dan lain-lain. (2) Mahasiswa Fakultas Ekonomi dan Bisnis di Daerah Istimewa Yogyakarta tahun angkatan 2016-2019. Mahasiswa Fakultas Ekonomi dan Bisnis pada angkatan 2016-2019 diasumsikan sudah memelajari dan mengambil mata kuliah yang berkaitan dengan keuangan.

Jenis data dalam penelitian ini adalah data primer yang bersumber dari kuesioner yang disebarkan. Sumber data dalam penelitian ini dari kuesioner yang disebar kepada responden yaitu Mahasiswa Fakultas Ekonomi dan Bisnis di Daerah Istimewa Yogyakarta melalui penyebaran kuesioner secara online menggunakkan google form. Kuesioner berisi indikator pernyataan yang berkaitan dengan variabel yang diteliti, dan pada akhirnya menghasilkan data kuantitatif (berbentuk angka) kemudian diolah menggunakan alat analisis statistik SmartPLS versi 3.0. Adapun skala pengukuran yang peneliti gunakan dalam mengukur indikator masing-masing variabel menggunakan skala likert dengan rincian: sangat tidak setuju skor 1, tidak setuju skor 2, netral skor 3, setuju skor 4, dan sangat setuju skor 5. Teknik analisis data menggunakan pengukuran outer model dengan convergent validity, discriminant validity, dan composite reliability. Metode yang digunakan untuk mengetahui pengaruh langsung adalah resampling bootstrap. Estimasi pengaruh tidak langsung secara simultan dengan menggunakan triangle PLS SEM Model untuk mengetahui pengaruh tidak langsung dengan adanya variabel mediasi. Pengujian hipotesis dalam penelitian ini menggunakan analisis regresi mediasi (mediated regresion analysis) yang dikembangkan oleh Baron dan Kenny (1986).

\section{HASIL DAN PEMBAHASAN}

\section{Estimasi Model Pengukuran (Outer Model) \\ Convergent Validity}

Nilai convergent validity ditunjukkan pada lampiran 1 dan gambar 2.

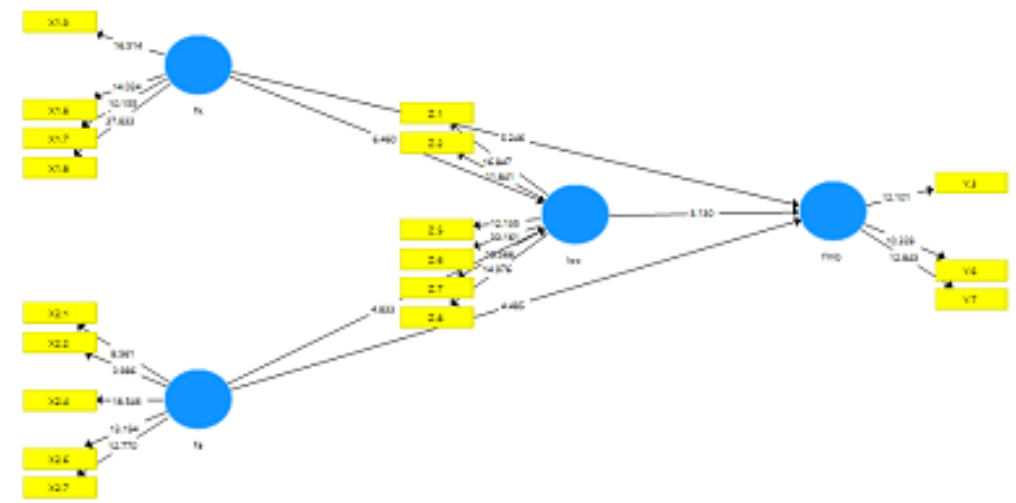

Gambar 2. MODEL STRUKTURAL

Lampiran 1 dan gambar 2 menunjukkan nilai loading factor dari masing-masing indikator variabel lebih besar dari 0,5, sehingga indikator-indikator tersebut dikatakan valid. Pada variabel financial knowledge indikator yang paling dominan atau terkuat adalah indikator FK 8. Kemudian pada variabel financial attitude indikator dominannya adalah indikator FA 4. Variabel financial management behavior menunjukkan indikator FMB 6 sebagai indikator dominan. Berikutnya variabel locus of control dengan indikator LOC 6 sebagai indikator dominan. 
Bella Cahyaningrum \& Muhammad Ali Fikri. Peran Pemediasi Locus of Control pada Pengaruh Financial Knowledge dan Financial Attitude terhadap Financial Management Behavior

\section{Discriminant Validity}

\section{Tabel 1.}

NILAI DISCRIMINANT VALIDITY

\begin{tabular}{ccccc}
\hline Indikator & FK(X1) & FA(X2) & FMB (Y) & LOC (Z) \\
\hline FK 3 & 0,779 & & & \\
FK 6 & 0,774 & & & \\
FK 7 & 0,777 & & & \\
FK 8 & 0,876 & & & \\
FA 1 & & 0,745 & & \\
FA 2 & & 0,810 & & \\
FA 4 & & 0,853 & & \\
FA 6 & & 0,764 & & \\
FA 7 & & 0,777 & 0,805 & \\
FMB 3 & & & 0,808 & 0,813 \\
FMB 6 & & & 0,763 & 0,792 \\
FMB 7 & & & 0,867 \\
LOC 1 & & & & 0,853 \\
LOC 2 & & & & \\
LOC 5 & & & & \\
LOC 6 & & & & \\
LOC 7 & & & \\
LOC 8 & & & \\
\hline
\end{tabular}

Sumber: output SmartPLS

Tabel 1 menjelaskan nilai cross loading dari masing-masing indikator dari variabel laten dalam penelitian ini sudah lebih besar dibandingkan dengan nilai cross loading dari indikator variabel lain. Artinya, variabel laten yang digunakan dalam penelitian ini memiliki discriminant validity yang baik.

\section{Composite Reliability dan Cronbach's Alpha}

Tabel 2.

NILAI COMPOSITE RELIABILITY DAN CRONBACH'S ALPHA

\begin{tabular}{cccc}
\hline Variabel & $\begin{array}{c}\text { Composit } \\
\text { Reliability }\end{array}$ & Cronbach's Alpha & Keterangan \\
\hline Financial Knowledge & 0,878 & 0,815 & Reliabel \\
Financial Attitude & 0,893 & 0,849 & Reliabel \\
Financial Management & 0,835 & 0,703 & Reliabel \\
Behavior & & & \\
Locus Of Control & 0,925 & 0,902 & Reliabel \\
\hline
\end{tabular}

Sumber: output SmartPLS

Tabel 2 menunjukkan nilai composite reliability dari masing-masing variabel $\geq 0,7$. Keseluruhan hasil cronbach's alpha menunjukkan nilai dari hasil model pengukuran (outer model) tersebut dapat dilakukan analisis selanjutnya untuk mengevaluasi model struktural (inner model).

\section{Hasil Pengujian Hipotesis}

Hasil pengujian hipotesis pada tabel 3 menunjukkan nilai original sampel positif yaitu 0,423. Artinya, apabila financial knowledge mengalami peningkatan, maka financial management behavior juga akan mengalami peningkatan. Kemudian nilai t-statistik menunjukkan lebih besar dari nilai t-tabel $(5,246>$ 1,96). Jadi hipotesis pertama yang mengatakan financial knowledge berpengaruh positif terhadap financial management behavior diterima.

Sebelum menguji mediasi, langkah yang ditekankan yaitu menguji pengaruh financial knowledge terhadap locus of control yang menunjukkan hasil nilai original sampel positif yaitu 0,497. Artinya, apabila financial knowledge mengalami peningkatan, maka locus of control juga akan mengalami 
peningkatan. Kemudian nilai t-statistik menunjukkan lebih besar dari t-tabel $(6,460>1,96)$. Jadi financial knowledge berpengaruh positif terhadap locus of control.

Selanjutnya menguji pengaruh locus of control terhadap financial management behavior menunjukkan nilai original sample positif yaitu 0,238. Artinya, apabila locus of control mengalami peningkatan, maka financial management behavior juga akan mengalami peningkatan. Kemudian nilai t-statistik menunjukkan lebih besar dari t-tabel $(3,130>1,96)$ sehingga dapat dikatakan locus of control berpengaruh positif terhadap financial management behavior.

Tabel 3.

HASIL UJI HIPOTESIS SECARA LANGSUNG DAN TIDAK LANGSUNG

\begin{tabular}{|c|c|c|c|c|c|c|}
\hline & $\begin{array}{c}\text { Original } \\
\text { Sample }(O)\end{array}$ & $\begin{array}{c}\text { Sample } \\
\text { Mean } \\
(M)\end{array}$ & $\begin{array}{l}\text { Standart } \\
\text { Deviasion } \\
\text { (STDEV) }\end{array}$ & $\begin{array}{c}\text { T Statistics } \\
(|O / S T D E V|)\end{array}$ & $\begin{array}{c}P \\
\text { Values }\end{array}$ & Keterangan \\
\hline $\mathrm{FK} \rightarrow \mathrm{FMB}$ & 0,423 & 0,434 & 0,081 & 5,246 & 0,000 & Diterima \\
\hline $\mathrm{FK} \rightarrow \mathrm{LOC}$ & 0,497 & 0,491 & 0,077 & 6,460 & 0,000 & Diterima \\
\hline $\mathrm{LOC} \rightarrow \mathrm{FMB}$ & 0,238 & 0,240 & 0,076 & 3,130 & 0,002 & Diterima \\
\hline $\begin{array}{c}\mathrm{FK} \rightarrow \mathrm{LOC} \\
\underset{\mathrm{FMB}}{\mathrm{LOC}}\end{array}$ & 0,118 & 0,115 & 0,035 & 3,411 & 0,029 & $\begin{array}{c}\text { Partial } \\
\text { Mediation }\end{array}$ \\
\hline $\mathrm{FA} \rightarrow \mathrm{FMB}$ & 0,384 & 0,377 & 0,086 & 4,485 & 0,000 & Diterima \\
\hline $\mathrm{FA} \rightarrow \mathrm{LOC}$ & 0,421 & 0,420 & 0,087 & 4,833 & 0,000 & Diterima \\
\hline $\begin{array}{c}\mathrm{FA} \rightarrow \mathrm{FOC} \\
\mathrm{FMB}\end{array}$ & 0,100 & 0,103 & 0,046 & 2,191 & 0,001 & $\begin{array}{c}\text { Partial } \\
\text { Mediation }\end{array}$ \\
\hline
\end{tabular}

Sumber: output SmartPLS

Berdasarkan tabel 3, locus of control memediasi pada pengaruh positif financial knowledge terhadap financial management behavior dengan hasil nilai original sampel 0,118 dan t-statistik sebesar 3,411 $>1,96$. Berdasarkan kriteria dari Baron \& Kenny (1986), locus of control dapat dikatakan mampu berperan sebagai pemediasi sebagian (partial mediation) pada pengaruh financial knowledge terhadap financial management behavior.

Hasil pengujian financial attitude berpengaruh positif terhadap financial management behavior menunjukkan nilai original sample positif yaitu 0,384. Artinya, apabila financial attitude mengalami peningkatan akan berpengaruh pada peningkatan financial management behavior. Selanjutnya nilai tstatistik menunjukkan lebih besar dari t-tabel $(4,485>1,96)$. Hipotesis ketiga yang mengatakan financial attitude berpengaruh positif financial management behavior diterima.

Langkah yang ditekankan sebelum menguji mediasi yaitu menguji pengaruh financial attitude terhadap locus of control. Hasil pengujian menunjukkan nilai original sampel positif yaitu 0,421. Artinya, jika financial attitude mengalami peningkatan, maka locus of control juga akan mengalami peningkatan. Selanjutnya nilai t-statistik menunjukkan lebih besar dari nilai t-tabel $(4,833>1,96)$. Jadi financial attitude berpengaruh positif terhadap locus of control.

Selanjutnya menguji pengaruh locus of control terhadap financial management behavior. Hasil pengujian menunjukkan nilai original sample positif yaitu 0,238 . Artinya, peningkatan pada locus of control juga akan memengaruhi peningkatan financial management behavior. Selanjutnya nilai tstatistik menunjukkan lebih besar dari t-tabel $(3,130>1,96)$. Hasil tersebut menunjukkan locus of control berpengaruh positif terhadap financial management behavior.

Pengujian locus of control memediasi pengaruh positif financial attitude terhadap financial management behavior diperoleh nilai original sampel positif yaitu 0,100 dan t-statistik 2,191. Berdasarkan kriteria dari Baron \& Kenny (1986) locus of control dapat dikatakan mampu berperan 
Bella Cahyaningrum \& Muhammad Ali Fikri. Peran Pemediasi Locus of Control pada Pengaruh Financial Knowledge dan Financial Attitude terhadap Financial Management Behavior

sebagai variabel mediasi sebagian (partial mediation) pada pengaruh financial attitude terhadap financial management behavior.

\section{Financial Knowledge Berpengaruh Positif terhadap Financial Management Behavior}

Hasil pengujian menunjukkan bahwa financial knowledge memiliki pengaruh positif terhadap financial management behavior. Financial knowledge yang dimiliki oleh Mahasiswa Fakultas Ekonomi dan Bisnis di Daerah Istimewa Yogyakarta dapat meningkatkan financial management behavior. Hal tersebut juga mengindikasikan Mahasiswa Fakultas Ekonomi dan Bisnis di Daerah Istimewa Yogyakarta memiliki pengetahuan yang cukup baik terkait keuangan yang dimilikinya. Financial knowledge yang tinggi akan berdampak pada financial management behavior yang baik juga sehingga mahasiswa akan lebih bijak dalam mengambil keputusan mengenai keuangan mereka. Tanpa adanya financial knowledge yang tinggi yang bereperan dalam mengarahkan financial management behavior, maka akan sukar bagi mahasiswa untuk melakukan pengambilan keputusan yang efektif dan bijak mengenai penggunaan uang yang dimilikinya guna mencapai kesuksesan dan kemakmuran baik saat ini maupun di masa yang akan datang.

Hasil dari penelitian ini mendukung hipotesis dan teori yang digunakan yaitu theory of planned behavior yang menjelaskan bahwa pengetahuan dapat menjadi latar belakang seseorang berperilaku. Hal tersebut dikarenakan tingginya financial knowledge yang dimiliki individu akan menjadikan individu dapat membuat keputusan mengenai keuangan secara tepat. Dengan begitu, individu akan mampu melakukan dan membentuk financial mangaement behavior dengan baik pula. Hasil penelitian ini didukung oleh penelitian terdahulu dari Mien \& Thao (2015), Robb \& Woodyard (2011), serta Andrew \& Linawati (2014) yang menjelaskan bahwa financial knowledge berpengaruh positif terhadap financial management behavior. Pada dasarnya individu dengan financial knowledge yang tinggi akan memiliki pengetahuan dan juga pemahaman yang tinggi dalam hal keuangan. Semakin tinggi financial knowledge yang dimiliki individu, maka kualitas keputusan keuangan yang diambil akan semakin baik dan dalam kehidupannya individu akan selalu mewujudkan financial management behavior yang baik juga (Asaff et al.,2019).

\section{Locus of Control Memediasi pada Pengaruh Positif Financial Knowledge terhadap Financial Management Behavior}

Sebelum membahas mediasi, langkah pertama yang ditekankan oleh Baron dan Kenny (1986) yaitu menguji pengaruh positif financial knowledge terhadap locus of control. Pengujian statistik menunjukkan hasil financial knowledge memiliki pengaruh positif terhadap financial management behavior. Hasil tersebut menjelaskan bahwa financial knowledge yang dimiliki oleh Mahasiswa Fakultas Ekonomi dan Bisnis di Daerah Istimewa Yogyakarta memberikan dampak yang besar dalam membentuk locus of control yang berhubungan dengan aspek keuangan.

Social learning theory yang dikembangkan oleh Bandura (1986) mengatakan bahwa perilaku terbentuk akibat dari proses kognitif dalam diri individu yang mana dalam penelitian ini proses kognitif yang dimaksud adalah financial knowledge. Ajzen (2011) dalam theory of planned behavior mengatakan perilaku dan niat merupakan sebuah fungsi dari sikap individu (attitude), kendali perilaku yang dipersepsikan (perceived behavioral control), dan norma subjektif (subjective norm). Dalam penelitian ini kendali perilaku digambarkan oleh financial knowledge, niat digambarkan oleh locus of control, dan perilaku diwakili oleh financial management behavior.

Individu dengan financial knowledge yang baik akan menciptakan locus of control yang tinggi. Individu akan mengontrol diri untuk selalu mengambil keputusan yang tepat dan cermat sesuai dengan pengetahuan mereka. Hal tersebut sesuai dengan teori yaitu semakin besar perceived behavioral control, maka locus of control dalam diri individu akan semakin kuat untuk melakukan perilaku yang sedang dipertimbangkan yang secara bersama-sama akan meningkatkan financial management behavior untuk kesejahteraan hidupnya. Locus of control merupakan konsep psikologi mengenai kepercayaan individu terhadap kejadian yang dapat berpengaruh kepada mereka. Dengan demikian, individu akan mengontrol diri untuk selalu mengambil keputusan yang tepat dan cermat 
sesuai dengan pengetahuan mereka, sehingga financial knowledge individu yang semakin tinggi akan berpengaruh pada tingkat locus of control yang semakin tinggi (Asih \& Khafid, 2020).

Financial knowledge tidak akan berguna secara maksimal apabila tidak diimbangi dengan rasa tanggungjawab pribadi yang tinggi. Perry \& Morris (2005) mengatakan sumber daya keuangan dan pengetahuan keuangan yang dimiliki oleh individu tidak dimanfaatkan secara maksimal karena mereka menilai mampu mengendalikan nasibnya. Financial knowledge yang diimbangi dengan locus of control akan membantu individu bertanggungjawab dengan financial management behavior (Perry \& Morris, 2005). Hasil penelitian yang dilakukan oleh Silvy \& Yulianti (2013) menjelaskan individu dengan financial knowledge yang tinggi berdampak pada perilaku untuk mengelola keuangan (financial management behavior) yang lebih bijak. Financial management behavior secara bijak juga harus diimbangi dengan locus of control yang baik (Silvy \& Yulianti, 2013). Penelitian terdahulu dari Al Kholillah \& Iramani (2013) serta Dwiastanti (2017) menunjukkan financial knowledge mempunyai pengaruh positif pada locus of control. Individu dengan financial knowledge yang tinggi mampu memelajari dan mengatur keuangannya dengan baik sehingga hal tersebut akan meningkatkan kemampuan locus of control atas hasil perilakunya (Ida \& Dwinta, 2010).

Pengujian statistik memerlihatkan hasil locus of control memiliki pengaruh positif pada financial management behavior. Hal tersebut menjelaskan locus of control yang dimiliki Mahasiswa Fakultas Ekonomi dan Bisnis di Daerah Istimewa Yogyakarta yang berhubungan dengan aspek keuangan memberikan dampak yang besar dalam mewujudkan financial management behavior. Penelitian terdahulu dari Jorgensen et al. (2017) serta Pradiningtyas \& Lukiastuti (2019) menunjukkan locus of control memiliki pengaruh positif terhadap financial management behavior. Locus of control menggambarkan pandangan individu terhadap kondisi yang akan datang dan memengaruhi keputusan yang akan diambilnya. Maka dari itu, locus of control harus dimiliki oleh masing-masing individu agar bertanggungjawab atas keputusan yang sudah diambilnya. Individu dengan tingkat locus of control yang tinggi, maka individu akan bertanggungjawab dengan keputusan keuangan yang diambilnya, dan sehingga tingginya locus of control akan berpengaruh terhadap financial management behavior yang semakin baik (Mien \& Thao, 2015).

Hipotesis kedua mengatakan locus of control mampu berperan sebagai mediasi pada pengaruh positif financial knowledge terhadap financial management behavior. Pengujian statistik menunjukkan hasil locus of control dapat berperan sebagai mediasi sebagian pada pengaruh financial knowledge terhadap financial mangement behavior. Adanya dukungan sebagian (parsial) pada pengaruh positif positif financial knowledge terhadap financial management behavior yang dimediasi oleh locus of control menunjukkan bahwa financial knowledge yang menjadi variabel independen tidak serta merta langsung berpengaruh pada financial management behavior yang menjadi variabel dependen tetapi dapat melalui variabel locus of control yang bisa menjadi variabel pemediasi. Dalam penelitian ini, locus of control hanya memediasi secara parsial pada pengaruh positif positif financial knowledge terhadap financial management behavior yang menunjukkan akan adanya faktor lain yang bisa turut memediasi pengaruh hubungan tersebut, namun tidak menutup kemungkinan jika financial knowledge telah diterapkan dengan baik maka hal ini akan meningkatkan locus of control dalam individu dan hasilnya akan meningkatkan financial management behavior.

Hasil pengujian ini mengindikasikan meningkatnya financial knowledge pada financial management behavior yang dimiliki Mahasiswa Fakultas Ekonomi dan Bisnis di Daerah Istimewa Yogyakarta akan meningkatkan locus of control dalam aspek keuangan, sehingga financial knowledge yang tinggi dapat membentuk financial management behavior yang baik dalam mengambil keputusan keuangan. Individu yang mempunyai financial knowledge yang baik akan meningkatkan kemampuan locus of control dalam pengelolaan keuangan dan secara bersama-sama dapat meningkatkan financial management behavior untuk kesejahteraan hidupnya. Hasil penelitian ini sejalan dengan penelitian terdahulu dari Al Kholilah \& Iramani (2013) menunjukkan locus of control mampu berperan sebagai mediasi pada pengaruh positif financial knowledge terhadap financial management behavior. Hal ini berarti individu dengan financial knowledge yang tinggi berpengaruh pada locus of control yang baik 
Bella Cahyaningrum \& Muhammad Ali Fikri. Peran Pemediasi Locus of Control pada Pengaruh Financial Knowledge dan Financial Attitude terhadap Financial Management Behavior

pula sehingga membentuk financial management behavior yang baik untuk kesejahteraan hidupnya (Rahmawati \& Haryono, 2020).

\section{Financial Attitude Berpengaruh Positif terhadap Financial Management Behavior}

Theory of planned behavior mengatakan sikap dianggap sebagai contoh pertama dari intensi perilaku (Ajzen, 2011). Sikap merupakan bentuk kepercayaan individu dalam mempresentasikan suatu perilaku. Sikap ditentukan oleh kepercayaan individu terhadap konsekuensi dari suatu perilaku (behavioral beliefs) dan diukur menggunakan hasil evaluasi konsekuensinya (out come evaluation). Sikap tersebut dipercaya mempunyai pengaruh secara langsung pada intensi perilaku individu dan dikaitkan dengan norma subjektif. Norma subjektif diperkirakan berperan sebagai suatu fungsi dari beliefs secara spesifik untuk mempresentasikan perilaku (Ajzen, 2011). Individu dengan sikap yang positif pada suatu pandangan atau pola pikir yang baik dalam bersikap mengenai keuangan maka akan memengaruhi untuk melakukan pengelolaan keuangan dengan baik sehingga membentuk financial management behavior yang baik juga dan dapat mengambil keputusan keuangan dengan tepat serta tidak merugikan.

Mien \& Thao (2015), Potrich et al. (2015), serta Pusparani \& Krisnawati (2019) yang menunjukkan bahwa financial attitude memiliki pengaruh positif pada financial management behavior. Individu dengan financial attitude yang baik menciptakan pandangan dan pola pikir tentang keuangan dimasa yang akan datang. Semakin baik financial attitude dari masing-masing individu, maka akan berdampak pada semakin baik financial management behavior yang dimiliki individu (Asaff et al.,2019). Financial attitude membentuk karakter dari setiap individu dalam pengelolaan keuangan dan bagaimana caranya mereka menanggapi permasalahan keuangan. Dengan demikian, individu dengan financial attitude yang semakin baik pada umumnya dalam masalah keuangan akan lebih bijak dalam mengambil keputusan khususnya yang berkaitan dengan financial management behavior (Asaff et al.,2019).

\section{Locus Of Control Memediasi pada Pengaruh Positif Financial Attitude terhadap Financial Management Behavior.}

Pengujian statistik menunjukkan hasil financial attitude memiliki pengaruh positif pada financial management behavior. Hal tersebut menjelaskan financial attitude yang dimiliki oleh Mahasiswa Fakultas Ekonomi dan Bisnis di Daerah Istimewa Yogyakarta memberikan dampak yang besar dalam membentuk locus of control yang berhubungan dengan aspek keuangan. Hasil penelitian ini konsisten dengan hasil penelitian terdahulu dari Jorgensen et al. (2017), Mien \& Thao (2015), Dwiastanti (2017), serta Pradiningtyas \& Lukiastuti (2019) yang menunjukkan financial attitude memiliki pengaruh positif terhadap locus of control. Individu dengan financial attitude yang baik akan memicu locus of control yang baik pula pada dirinya (Dwiastanti 2017).

Financial attitude mewakili attitude toward the behavior (sikap) dan locus of control mewakili niat (intention). Financial attitude yang dimiliki mahasiswa akan memengaruhi tingkat pengendalian diri (locus of control) yang mereka miliki. Individu akan mengontrol diri agar selalu memiliki perasaan untuk selalu melakukan kegiatan keuangan yang tidak merugikan. Oleh karena itu, apabila financial attitude yang dimiliki individu semakin baik, maka locus of control individu tersebut juga akan semakin kuat. Hasil penelitian Dwiastanti (2017) menjelaskan perasaan untuk mendukung atau tidak mendukung suatu perilaku keuangan ini akan membentuk locus of control pada diri individu. Apabila financial attitude yang dimiliki individu semakin baik, maka tingkat locus of control yang dimilikinya akan semakin tinggi juga (Asih \& Khafid, 2020). Mahasiswa dengan financial attitude yang baik akan dapat mengendalikan diri untuk selalu bijak dalam menggunakan uangnya agar uang yang dimiliki tidak hanya memberikan manfaat secara finansial tetapi juga memberikan manfaat ekonomi dalam kehidupannya sehari-hari.

Locus of control memiliki pengaruh pada financial management behavior. Pengujian statistik menunjukkan hasil locus of control memiliki pengaruh positif pada financial management behavior. Hasil tersebut sejalan dengan penelitian terdahulu dari Jorgensen et al. (2017) serta Pradiningtyas \& Lukiastuti (2019) dengan hasil locus of control memiliki pengaruh positif pada financial management 
behavior. Locus of control menggambarkan pandangan individu terhadap kondisi yang akan datang dan mempengaruh keputusan yang akan diambilnya. Maka dari itu, locus of control harus dimiliki oleh masing-masing individu agar bertanggungjawab atas keputusan yang sudah diambilnya. Individu dengan tingkat locus of control yang tinggi, maka individu akan bertanggungjawab dengan keputusan keuangan yang diambilnya, dan sehingga tingginya locus of control akan berpengaruh pada financial management behavior yang semakin baik (Mien \& Thao, 2015).

Pengujian statistik menunjukkan locus of control dapat berperan sebagai mediasi sebagian pada pengaruh financial attitude terhadap financial management behavior. Adanya dukungan sebagian (parsial) pada pengaruh positif positif financial attitude terhadap financial management behavior yang dimediasi oleh locus of control menunjukkan bahwa financial attitude yang menjadi variabel independen tidak serta merta langsung berpengaruh pada financial management behavior yang menjadi variabel dependen tetapi dapat melalui variabel locus of control yang bisa menjadi variabel pemediasi. Dalam penelitian ini, locus of control hanya memediasi secara parsial pada pengaruh positif positif financial attitude terhadap financial management behavior yang menunjukkan akan adanya faktor lain yang bisa turut memediasi pengaruh hubungan tersebut, namun tidak menutup kemungkinan jika financial attitude telah diterapkan dengan baik maka hal ini akan meningkatkan locus of control dalam individu dan secara bersama-sama akan meningkatkan financial management behavior.

Hasil temuan mengindikasikan meningkatnya financial attitude yang dimiliki Mahasiswa Fakultas Ekonomi dan Bisnis di Daerah Istimewa Yogyakarta akan meningkatkan locus of control dalam aspek keuangan sehingga locus of control yang baik mampu menciptakan financial management behavior yang baik juga terutama yang berkaitan dengan pengambilan keputusan keuangan. Hasil penelitian yang dilakukan Aminatuzzahra (2014), Amanah et al.,(2016), serta Pradiningtyas \& Lukiastuti (2019) menunjukkan hasil locus of control mampu berperan sebagai mediasi pada pengaruh positif financial attitude terhadap financial management behavior. Semakin baik financial attitude yang dimiliki individu akan semakin kuat pula locus of control individu untuk melakukan atau tidak melakukan tindakan yang sedang dipertimbangkan. Perasaan untuk mendukung atau tidak mendukung mengenai pandangan keuangan ini akan membentuk locus of control pada diri individu. Hal tersebut akhirnya akan menghasilkan financial management behavior yang bertanggungjawab. Pada akhirnya terdapat keterkaitan bahwa semakin tinggi tingkat financial attitude yang dimiliki oleh individu akan membentuk locus of control yang baik sehingga pada akhirnya dapat menciptakan financial management behavior yang baik pula (Dwiastanti, 2017).

\section{KESIMPULAN}

Berdasarkan hasil analisis data yang sudah dilakukan, maka diperoleh kesimpulan bahwa financial knowledge berpengaruh positif terhadap financial management behavior, locus of control memediasi pada pengaruh positif financial knowledge terhadap financial management behavior, financial attitude berpengaruh positif terhadap financial management behavior, dan locus of control memediasi pada pengaruh positif financial attitude terhadap financial management behavior. Peneliti ingin memberikan beberapa keterbatasan dan saran untuk penelitian berikutnya yaitu: pertama, penelitian ini menggunakan teknik purposive sampling dan akan lebih baik jika pada penelitian selanjutnya menggunakkan jumlah sampel yang lebih banyak sehingga bisa digeneralisasi. Pada penelitian ini tidak semua sampel dalam populasi memiliki kesempatan yang sama untuk dipilih sebagai sampel, karena menggunakan teknik non random sampling. Konsekuensinya, generalisasi hasil penelitian harus dilakukan secara hati-hati. Oleh karena itu, penelitian yang akan datang sebaiknya menggunakan teknik random sampling sehingga tingkat generalisasi hasil penelitian menjadi lebih tinggi. Penelitian selanjutnya dapat menggunakan variabel moderasi atau menambahkan variabel seperti income (Asih \& Khafid, 2020) dan demografi (Rizkiawati \& Haryono, 2018). Penelitian ini terbatas pada mahasiswa Fakultas Ekonomi dan Bisnis di Daerah Istimewa Yogyakarta. Penelitian yang akan datang diharapkan memerluas daerah penelitian dan menggunakan subjek penelitian yang 
Bella Cahyaningrum \& Muhammad Ali Fikri. Peran Pemediasi Locus of Control pada Pengaruh Financial Knowledge dan Financial Attitude terhadap Financial Management Behavior

lain seperti pelaku Usaha Mikro Kecil Menengah atau UMKM (Humaira \& Sagoro, 2018) dan masyarakat luas (Rizkiawati \& Haryono, 2018).

\section{DAFTAR PUSTAKA}

Ajzen, I. (2011). The Theory of Planned Behaviour: Reactions and Reflections. Psychology \& Health, 26(9), 1113-1127.

Al Kholilah, N., \& Iramani, R. (2013). Studi Financial Management Behavior pada Masyarakat Surabaya. Journal of Business and Banking, 3(1), 69-80.

Amanah, E., Rahadian, D., \& Iradianty, A. (2016). Pengaruh Financial Knowledge, Financial Attitude dan External Locus of Control terhadap Personal Financial Management Behavior pada Mahasiswa S1 Universitas Telkom. eProceedings of Management.3 (2).1228-1235.

Aminatuzzahra, A. (2014). Perception Effect of Financial Knowledge, Financial Attitudes, Social Demography Against Financial Behavior in Individual Investment Decision Making. Journal of Business Strategy, 23(2).70-96. DOI: 10.14710/jbs.23.2.70-96

Andrew, V., \& Linawati, N. (2014). Hubungan Faktor Demografi dan Pengetahuan Keuangan dengan Perilaku Keuangan Karyawan Swasta di Surabaya. Finesta, 2(2), 35-39.

Ariani, S., Rahmah, P. A. A. A., Putri, Y. R., Rohmah, M., Budiningrum, A., \& Lutfi. (2016). Pengaruh Literasi Keuangan, Locus of Control, dan Etnis terhadap Pengambilan Keputusan Investasi. Journal of Business and Banking, 5(2), 257-270.

Asaff, R., Suryati, S., \& Rahmayani, R. (2019). Pengaruh Financial Attitude dan Financial Knowledge terhadap Financial Management. JEMMA (Jurnal of Economic, Management and Accounting), 2(2), 9-22.

Asih, S. W., \& Khafid, M. (2020). Pengaruh Financial Knowledge, Financial Attitude dan Income terhadap Personal Financial Management Behavior melalui Locus of Control sebagai Variabel Intervening. Economic Education Analysis Journal, 9(3), 748-767.

Aydemir, S. D., \& Aren, S. (2017). Do The Effects of Individual Factors on Financial Risk-Taking Behavior Diversify with Financial Literacy?. Kybernetes, 46(10), 1706-1734.

Bandura, A. (1986). Social Foudation of Thought and Action. New Jersey:Prentice-Hall.

Baron, R. M., \& Kenny, D. A. (1986). The Moderator-Mediator Variable Distinction in Social Psychological Research: Conceptual, Strategic, and Statistical Considerations. Journal of Personality and Social Psychology, 51(6), 1173-1182.

Borden, L. M., Lee, S. A., Serido, J., \& Collins, D. (2008). Changing College Students' Financial Knowledge, Attitudes, and Behavior through Seminar Participation. Journal of Family and Economic Issues, 29(1), 23-40.

Budiono, E. (2020). Analisis Financial Knowledge, Financial Attitude, Income, Locus of Control, Financial Management Behavior Masyarakat Kota Kediri. Jurnal Ilmu Manajemen (JIM), 8(1).284-295.

Dwiastanti, A. (2017). Analysis of Financial Knowledge and Financial Attitude on Locus of Control and Financial Management Behavior. MBR (Management and Business Review), 1(1), 1-8. 
Henseler, J., Ringle, C. M., \& Sinkovics, R. R. (2009). The use of partial least squares path modeling in international marketing. In Advances in International Marketing|Adv. Int. Mark. Vol. 20, pp. 277-319). https://doi.org/10.1108/S1474-7979(2009)0000020014

Herawati, N. T. (2015). Kontribusi Pembelajaran di Perguruan Tinggi dan Literasi Keuagan Terhadap Perilaku Keuangan Mahasiswa. Jurnal Pendidikan dan Pengajaran, 48, 1-3.

Herdjiono, I., \& Damanik, L. A. (2016). Pengaruh Financial Attitude, Financial Knowledge, Parental Income terhadap Financial Management Behavior. Jurnal Manajemen Teori dan Terapan. Journal of Theory and Applied Management, 9(3), 226-241.

Hilgert, M. A., Hogarth, J. M., \& Beverly, S. G. (2003). Household Financial Management: The Connection between Knowledge and Behavior. Federal Reserve Bulletin, 89, 309-322.

Humaira, I., \& Sagoro, E. M. (2018). Pengaruh Pengetahuan Keuangan, Sikap Keuangan, dan Kepribadian terhadap Perilaku Manajemen Keuangan pada Pelaku UMKM Sentra Kerajinan Batik Kabupaten Bantul. Nominal: Barometer Riset Akuntansi dan Manajemen, 7(1), 96-110.

Huston, S. J. (2010). Measuring Financial Literacy. Journal Of Consumer Affairs, 44(2), 296-316.

Ida, I. D. A., \& Dwinta, C. Y. (2010). Pengaruh Locus Of Control, Financial Knowledge, Income terhadap Financial Management Behavior. Jurnal Bisnis dan Akuntansi, 12(3), 131-144.

Jorgensen, B. L., Rappleyea, D. L., Schweichler, J. T., Fang, X., \& Moran, M. E. (2017). The financial behavior of emerging adults: A family financial socialization approach. Journal of Family and Economic Issues, 38(1), 57-69.

Marsh, B. A. (2006). Examining The Personal Finance Attitudes, Behaviors, and Knowledge Levels of First-Year and Senior Students at Baptist Universities in The State of Texas. (Doctoral dissertation, Bowling Green State University).

Mien, N. T. N., \& Thao, T. P. (2015). Factors Affecting Personal Financial Management Behaviors: Evidence from Vietnam. In Proceedings of the Second Asia-Pacific Conference on Global Business, Economics, Finance and Social Sciences (AP15Vietnam Conference) (10-12).

Nobriyani, A. P., \& Haryono, N. A. (2019). Faktor-Faktor yang Memengaruhi Financial Management Behavior pada Keluarga TKI di Kabupaten Ponorogo. Jurnal Ilmu Manajemen (JIM), 7(3).841856.

Pangkalan Data Pendidikan Tinggi. (2020). https://pddikti.kemdikbud.go.id/.diakses pada 2 Maret 2021.

Pankow, D. (2003). Financial Values, Attitudes and Goals. North Dakota: State University Fargo.

Perry, V. G., \& Morris, M. D. (2005). Who is in Control? Yhe Role of Self-Perception, Knowledge, and Income in Explaining Consumer Financial Behavior. Journal of Consumer Affairs, 39(2), 299-313.

Potrich, A. C. G., Vieira, K. M., \& Mendes-Da-Silva, W. (2015). Development of A Financial Literacy Model for University Students. Management Research Review, 39(3), 356-376.

Pradiningtyas, T. E., \& Lukiastuti, F. (2019). Pengaruh Pengetahuan Keuangan dan Sikap Keuangan terhadap Locus of Control dan Perilaku Pengelolaan Keuangan Mahasiswa Ekonomi. Jurnal Minds: Manajemen Ide Dan Inspirasi, 6(1), 96-112. 
Bella Cahyaningrum \& Muhammad Ali Fikri. Peran Pemediasi Locus of Control pada Pengaruh Financial Knowledge dan Financial Attitude terhadap Financial Management Behavior

Pusparani, A., \& Krisnawati, A. (2019). Analisis Pengaruh Financial Literacy dan Financial Attitude terhadap Financial Behavior pada Siswa Sekolah Menengah Pertama di Kota Bandung. Jurnal Mitra Manajemen, 3(1), 72-83.

Rahmawati, N. W., \& Haryono, N. S. (2020). Analisis Faktor yang Memengaruhi Financial Management Behavior dengan Mediasi Locus Of Control. Jurnal Ilmu Manajemen, 8(2).549563.

Rizkiawati, N. L., \& Haryono, N. A. (2018). Pengaruh Demografi, Financial Knowledge, Financial Attitude, Locus of Control dan Financial Self-Efficacy terhadap Financial Management Behavior Masyarakat Surabaya. Jurnal Ilmu Manajemen (JIM), 6(3). 93-107.

Robb, C. A., \& Woodyard, A. S. (2011). Financial Knowledge and Best Practice Behavior. Journal of Financial Counseling and Planning, 22(1), 60-70.

Shahrabani, S. (2012). The Effect of Financial Literacy and Emotions on Intent to Control Personal Budget: A Study among Israeli College Students. International Journal of Economics and Finance, 4(9), 156-163.

Silvy, M., \& Yulianti, N. (2013). Sikap Pengelola Keuangan dan Perilaku Perencanaan Investasi Keluarga di Surabaya. Journal of Business and Banking, 3(1), 57-68.

Sriwidodo, R. P. U. (2015). Pengaruh Pengetahuan Keuangan dan Pengalaman Keuangan terhadap Perilaku Perencanaan Investasi dengan Self Control sebagai Variabel Moderating. Jurnal Ekonomi dan Kewirausahaan, 15(1).28-37.

Tang, N., \& Baker, A. (2016). Self-Esteem, Financial Knowledge and Financial Behavior. Journal of Economic Psychology, 54, 164-176.

Zakaria, R. H., Jaafar, N. I. M., \& Marican, S. (2012). Financial Behavior and Financial Positions: A Structural Equation Modelling Approach. Middle-East Journal of Scientific Research, 12(10), 1396-1402.

\section{Lampiran 1. NILAI CONVERGENT VALIDITY}

\begin{tabular}{ccccc}
\hline Variabel & $\boldsymbol{A V E}$ & Indikator & Loading Factor & Keterangan \\
\hline Financial & 0,644 & FK 3 & 0,779 & Valid \\
Knowledge & & FK 6 & 0,774 & Valid \\
(FK) & & FK 7 & 0,777 & Valid \\
& & FK 8 & 0,876 & Valid \\
Financial & 0,625 & FA 1 & 0,745 & Valid \\
Attitude & & FA 2 & 0,810 & Valid \\
(FA) & & FA 4 & 0,853 & Valid \\
& & FA 6 & 0,764 & Valid \\
Financial & \multirow{2}{*}{0,628} & FA 7 & 0,777 & Valid \\
Management & & FMB 3 & 0,805 & Valid \\
Behavior & & FMB 6 & 0,808 & Valid \\
(FMB) & & FMB 7 & 0,763 & Valid \\
Locus OfControl & 0,673 & LOC 1 & 0,813 & Valid \\
(LOC) & & LOC 2 & 0,770 & Valid \\
& & LOC 5 & 0,792 & Valid \\
& & LOC 6 & 0,867 & Valid \\
& & LOC 7 & 0,853 & Valid \\
\hline
\end{tabular}

